\title{
Mesenchymal Stem Cells Attenuate Lipopolysaccharide- Induced Inflammatory Response in Human Uterine Smooth Muscle Cells
}

\author{
Arunmani Mani, PhD ${ }^{1}$ John W. Hotra, BS ${ }^{1}$ Sean C. Blackwell, MD ${ }^{1}$ Laura Goetzl, MD, MPH ${ }^{1}$ \\ Jerrie S. Refuerzo, MD ${ }^{1}$ \\ ${ }^{1}$ Division of Maternal Fetal Medicine, Department of Obstetrics, \\ Gynecology and Reproductive Sciences, UT Health-McGovern \\ Medical School, Houston, Texas \\ Am J Perinatol Rep 2020;10:e335-e341.

\begin{abstract}
Address for correspondence Arunmani Mani, PhD, Division of Maternal Fetal Medicine, Department of Obstetrics, Gynecology and Reproductive Sciences, UTHealth- McGovern Medical School, 6431 Fannin, MSB 3.618, Houston, TX 77030
\end{abstract} \\ (e-mail: Arunmani.mani@uth.tmc.edu).
}

\author{
Abstract \\ Keywords \\ - mesenchymal stem \\ cells \\ - lipopolysaccharide \\ - inflammatory \\ response \\ - cytokines \\ - preterm birth
}

Objective The aim of this study was to determine if mesenchymal stem cells (MSCs) would suppress the inflammatory response in human uterine cells in an in vitro lipopolysaccharide (LPS)-based preterm birth (PTB) model.

Study Design Cocultures of human uterine smooth muscle cells (HUtSMCs) and MSCs were exposed to $5 \mu \mathrm{g} / \mathrm{mL}$ LPS for 4 hours and further challenged with $1 \mu \mathrm{g} / \mathrm{mL}$ LPS for a subsequent 24 hours. Key elements of the parturition cascade regulated by toll-like receptors (TLRs) through activation of mitogen-activated protein kinases (MAPKs) were quantified in culture supernatant as biomarkers of MSC modulation.

Results Coculture with MSCs significantly attenuated TLR-4, p-JNK, and p- extracellular signal-regulated kinase $1 / 2$ (ERK1/2) protein levels compared with HUtSMCs monoculture $(p=0.05)$. In addition, coculture was associated with significant inhibition of proinflammatory cytokines interleukin (IL)-6 and IL-8 $(p=0.0001)$ and increased production of anti-inflammatory cytokines IL-10 and transforming growth factor (TGF)$\beta 1(p=0.0001)$.

Conclusion MSCs appear to play a role in significantly attenuating LPS-mediated inflammation via alteration of down-stream MAPKs. MSCs may represent a novel, cellbased therapy in women with increased risk of inflammatory-mediated preterm birth.
Preterm birth (PTB) $<37$ weeks occurs in approximately $10 \%$ of births in the United States and is the leading cause of neonatal mortality and morbidity. ${ }^{1-4}$ Although the mechanisms are multifactorial, infection and inflammation play a critical role in a large proportion of PTB. $^{3,5}$ Parturition in itself is an inflammatory process ${ }^{6}$ and pathologic activation of the inflammatory response that regulates parturition initiation contributes to PTB. ${ }^{1,3,7,8}$ The majority of PTBs are spontaneous owing to dysfunctional activation of uterine activity or preterm premature rupture of the fetal membranes (PPROMs). ${ }^{9-11} \mathrm{~A}$ proinflammatory environment is a common phenomenon in both infectious and idiopathic PTB. Toll-like receptor-4 (TLR-4) mediates innate immune recognition and response to the bacterial endotoxin lipopolysaccharide (LPS). ${ }^{12-14}$ TLR-4 activation is thought to play a crucial role in preterm delivery and normal labor. ${ }^{15-17}$ Both acute inflammation and chronic inflammation (such as stress) appear to contribute to TLR-4mediated preterm birth pathways. LPS-mediated stimulation of TLR-4 leads to activation of nuclear factor (NF)-KB signaling pathway and proinflammatory cytokines. ${ }^{18}$ TLR-4 activates mitogen-activated protein kinases (MAPKs) including c-Jun $\mathrm{N}$-terminal kinase (JNK), extracellular signal-regulated kinase (ERK1/2), and IKB- $\alpha$ that culminates in activation of the transcription factor NF-KB, ultimately stimulating the production of received

March 27, 2020

accepted

April 24, 2020
DOI https://doi.org/

10.1055/s-0040-1715166. ISSN 2157-6998.
Copyright $\odot 2020$ by Thieme Medical Publishers, Inc., 333 Seventh Avenue, New York, NY 10001, USA. Tel: +1(212) 760-0888.
License terms

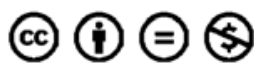


proinflammatory cytokines. ${ }^{19,20}$ The association between elevated levels of proinflammatory cytokines and preterm birth is well evidenced. ${ }^{16,21}$ Myometrial cells are capable of producing interleukin (IL)-6 and IL-8 in synergy with infiltrating immune cells in due course stimulating myometrial contractility. ${ }^{22}$ Lei et $\mathrm{al}^{23}$ affirm the association between the inflammatory response and human parturition through myometrial release of proinflammatory cytokines. In addition, the role of MAPKs activation in the human cervix and placenta preceding labor have been described. ${ }^{24,25}$ Parallel studies in LPS-based rodent models substantiate activation of TLR- 4 signaling pathway and proinflammatory cytokines in the induction of PTB. ${ }^{15}$ LPS-mediated activation of TLR- 4 followed by MAPK protein activation triggers production of proinflammatory cytokines, activating the NF-KB pathway, and increasing the risk of preterm birth. ${ }^{17,26}$

Mesenchymal stem cells (MSCs) are unique multipotent cells that possess powerful immunomodulatory properties. ${ }^{27}$ MSCs are currently being tested in clinical trials at different phases for a variety of pathologic conditions including graft versus host disease, inflammatory airway diseases, and inflammatory bowel diseases. ${ }^{28,29}$ Given the growing acceptance of MSCs as a biotherapeutic, we hypothesized that MSCs could be beneficial for ameliorating uterine inflammation and reducing pathologic activation of contractions. MSCs could have potential benefit in clinical situations where infection does not prompt therapeutic delivery such as idiopathic preterm labor, uterine fibroid degeneration, placental abruption, intra-abdominal inflammation/appendicitis, and PPROM without infection among others. The objective of this study was to determine whether MSCs would suppress the inflammatory response in human uterine smooth muscle cells (HUtSMCs) exposed to lipopolysaccharide (LPS) in vitro.

\section{Materials and Methods}

\section{Cell Culture}

HUtSMCs and MSCs were purchased from PromoCell, (Heidelberg, Germany). They were grown in smooth muscle cell growth medium and MSC growth medium with supplement mix (PromoCell, Heidelberg, Germany), respectively, at $37^{\circ} \mathrm{C}$ in a humidified atmosphere of $95 \%$ air and $5 \% \mathrm{CO}_{2}$. At $90 \%$ confluent monolayer, HUtSMCs were plated at a density of $2 \times 10^{5}$ cells per well in a 12 well plate (Corning, NY) and treated with LPS. HUtSMCs were divided into the following experimental groups: (1) control (saline), (2) LPS (no MSCs), (3) MSC coculture (no LPS), and (4) LPS and MSC coculture. Following treatment with LPS or vehicle, HUtSMCs were monocultured or cocultured with MSCs and plated at a total cell density of $2 \times 10^{5}$ cells (Corning transwell; $0.4 \mu \mathrm{m}$ pore size; - Fig. 1A). After 24 hours, culture supernatants from the myometrial cells were collected, centrifuged at $1,500 \mathrm{rpm}$ for $10 \mathrm{~min}$ to remove any cell contamination, and stored at $-80^{\circ} \mathrm{C}$ until further use. LPS (Escherichia coli 055:B5) was purchased from Sigma Aldrich (St. Louis, MO). Concentration for the LPS in in vitro model was determined by dose kinetic studies as follows: HUtSMCs were challenged with $5 \mu \mathrm{g} / \mathrm{mL}$ LPS for 4 hours followed by different doses of either $100 \mathrm{ng} / \mathrm{mL}$, 1 or
$2 \mu \mathrm{g} / \mathrm{mL}$ LPS for 24 hours to elicit an inflammatory response ( - Fig. 1B-D). Based on the dose kinetic study, $5 \mu \mathrm{g} / \mathrm{mL}$ LPS for 4 hours, followed by $1 \mu \mathrm{g} / \mathrm{mL}$ LPS for another 24 hours was used in all subsequent experiments based on the maximal stimulation of the IL-6.

\section{Cytokine Measurement by ELISA}

Proinflammatory cytokines were measured including IL-6 and IL-8. Anti-inflammatory cytokines were also measured including IL-10 and TGF- $\beta 1$. Secreted protein levels were quantified using standard enzyme-like immune sorbent assay (ELISA) methodology performed in accordance with the guidelines supplied by the manufacturer (R\&D Systems, Minneapolis, MN). The minimum detectable and quantifiable amount for IL-6 was $3.0 \mathrm{pg} / \mathrm{mL}$, whereas for IL-8, IL-10, and TGF- $\beta 1$, it was $31.3 \mathrm{pg} / \mathrm{mL}$.

\section{Western Blot Analysis}

To determine the possible mechanism by which MSCs attenuated proinflammatory cytokines, we examined the expression levels of TLR-4 and specific MAPKs, as LPS-mediated stimulation of TLR-4 leads to activation of MAPKs culminating in the production of proinflammatory cytokines. Protein expression was assessed by Western blot analysis, wherein, HUtSMCs were washed with ice-cold phosphate buffered saline (PBS) and lysed with radioimmunoprecipitation assay (RIPA) buffer (Boston Bio-products, Ashland, MA), supplemented with protease inhibitors (Halt Protease inhibitor 100X, Thermo Scientific, Waltham, MA). Concentrations of sample protein were determined by BCA protein assay (Pierce, Rockford, IL). Protein extracts were resolved on 10 to $12 \%$ (sodium dodecyl sulfate) SDS-polyacrylamide gel electrophoresis (SDS-PAGE) and transferred to nitrocellulose (NC) membranes, which were blocked with 5\% Bovine Serum Albumin (BSA). The NC membranes were probed with primary antibodies against TLR-4, (Santa Cruz Biotechnology, Dallas, TX), total ERK1/2, p-ERK1/2, total JNK, p-JNK, and IкB- $\alpha$ (Cell Signaling Technology, Danvers, $\mathrm{MA})$, and incubated overnight at $4^{\circ} \mathrm{C}$. The membranes were washed in PBS of $0.1 \%$ Tween 20 and incubated with HRPconjugated secondary antibodies for 1 hour at room temperature. After successive washes, the membranes were developed using Clarity Western Enhanced Chemiluminescence (ECL) blotting substrate (Bio-Rad, Hercules, CA). Quantitative analysis of the immunoblots was performed using LI-COR C-DiGit Blot Scanner (LI-COR Biosciences; Lincoln, NE) and band intensities were measured by densitometry analysis. All the samples were normalized for protein loading using $\beta$-actin.

\section{Data Analysis}

Data are expressed as mean \pm standard error of the mean (SEM). Statistical analysis was performed using Graph-Pad Prism (version 6.0, La Jolla, CA). Comparisons of cytokines expression among the above four groups were analyzed using one-way analysis of variance (ANOVA) with Tukey's post hoc test. Comparison of MAPK levels were compared between myometrial cells exposed to LPS and those exposed to LPS and cocultured with MSCs. A $p$-value of $<0.05$ was considered statistically significant. 


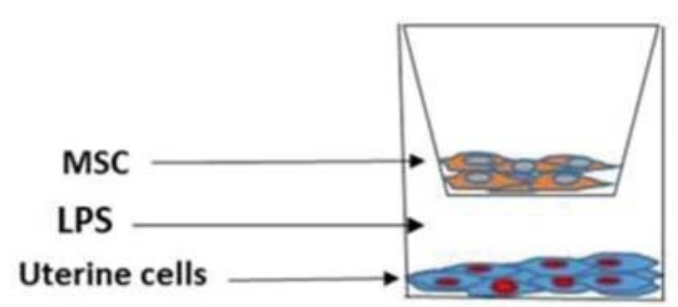

A

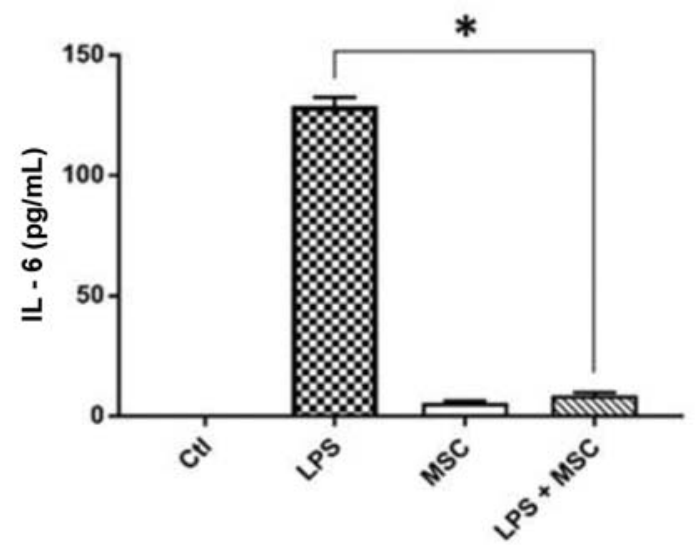

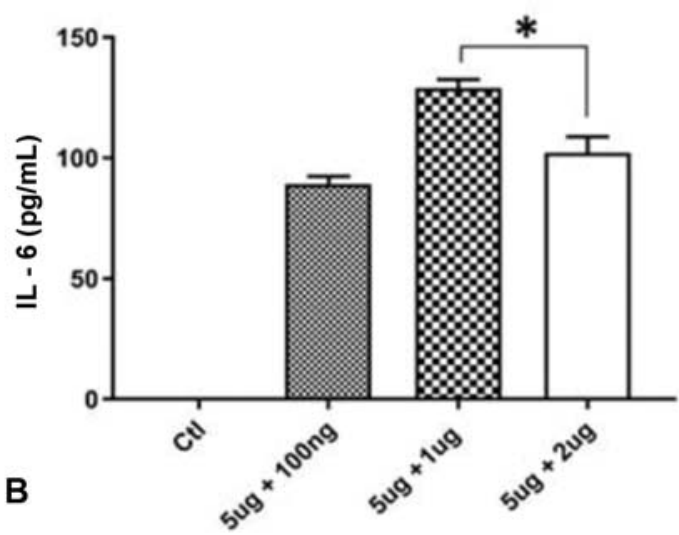

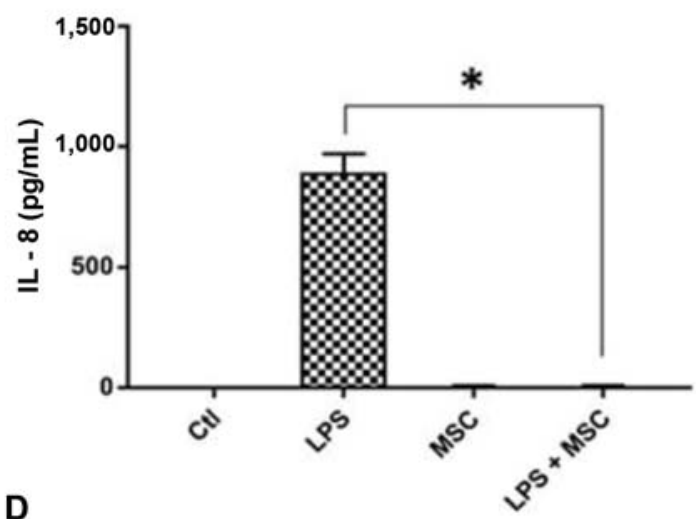

Fig. 1 Mesenchymal stem cells (MSC) attenuated proinflammatory cytokines IL-6 and IL-8 in LPS treated uterine cells. Uterine cells cocultured with mesenchymal stem cells in transwell inserts. (A) Uterine cells exposed to lipopolysaccharide showed significant increase in IL-6. (B) MSCs coculture attenuate the expression of IL-6 and IL-8 (C and D). Data represent mean \pm SEM. ${ }^{*} p=0.0001$. CtI, control; IL, interleukin; LPS, lipopolysaccharide; SEM, standard error of the mean.

\section{Results}

Attenuation of Proinflammatory Cytokines by MSCs Cytokine levels in LPS-induced HUtSMCs were altered in the presence of MSCs (-Fig. 1A, C, D). HUtSMCs exposed to LPS and cocultured with MSCs exhibited significant attenuation in the expression levels of IL-6 (LPS + MSC: $8.8 \pm 0.5 \mathrm{pg} / \mathrm{mL}$ vs. LPS alone: $128.9 \pm 2.1 \mathrm{pg} / \mathrm{mL}, p=0.0001)$, and IL-8 (LPS + MSC: $9.43 \pm 1.0 \mathrm{pg} / \mathrm{mL}$ vs. LPS alone: $894.2 \pm 45.1$ $\mathrm{pg} / \mathrm{mL}, p=0.0001$ )

\section{Attenuated Phosphorylation of JNK and ERK1/2 by MSCs} The expression of TLR-4 was increased in HUtSMCs when exposed to LPS (-Fig. 2A). This effect was significantly inhibited when LPS exposed HUtSMCs were cocultured with MSCs, (LPS+ MSC: $1.25 \pm 0.1 \mathrm{pg} / \mathrm{mL}$ vs. LPS alone: $1.77 \pm 0.09 \mathrm{pg} / \mathrm{mL}, p=0.05)$. Similarly, these observations were seen with specific MAPK expressions (-Fig. 2B, C) including significant reductions in the expression of p-JNK, (LPS + MSC: $0.76 \pm 0.15 \mathrm{pg} / \mathrm{mL}$ vs. LPS alone: $1.57 \pm 0.05$ $\mathrm{pg} / \mathrm{mL}, p=0.0001$ ) and p-ERK1/2 (LPS + MSC: $1.24 \pm 0.36$ $\mathrm{pg} / \mathrm{mL}$ vs. LPS alone: $3.25 \pm 0.19 \mathrm{pg} / \mathrm{mL}, p=0.0001)$. In contrast, the expression levels of ІкВ- $\alpha$ was significantly decreased with LPS exposure, but was significantly increased when cocultured with MSC, (LPS + MSC: $1.11 \pm 0.03 \mathrm{pg} / \mathrm{mL}$ vs. LPS: $0.68 \pm 0.05 \mathrm{pg} / \mathrm{mL}, p=0.006$; - Fig. 2D). Western blot patterns for TLR-4 and MAPK's are shown (-Fig. 2E).

\section{Increased Expression of Anti-inflammatory Cytokines IL-10 and TGF- $\beta 1$}

Even in the absence of LPS, MSC coculture was associated with increased levels of both IL-10 and TGF- $\beta 1$ levels by HUtSMCs ( - Fig. 3A, B). However, with LPS treatment, MSC coculture was associated with significantly greater increases in both IL10 (LPS + MSC: $81.63 \pm 6.23 \mathrm{pg} / \mathrm{mL}$ vs. MSC alone: $36.9 \pm 4.5$ $\mathrm{pg} / \mathrm{mL}, \quad p=0.0001$; -Fig. 3A) and TGF- $\beta 1$ (LPS + MSC: $1,538.0 \pm 74.97 \mathrm{pg} / \mathrm{mL}$ vs. MSC alone: $969.5 \pm 38.8 \mathrm{pg} / \mathrm{mL}$; $p=0.0001$, - Fig. 3B).

\section{Discussion}

Our work provides evidence that MSCs play a prime role in significantly attenuating LPS-mediated inflammation via alteration of down-stream mitogen-activated kinase pathways (-Fig. 4). Further, our studies confirm the prior work in other models that MSCs suppress inflammatory activation of JNK and 

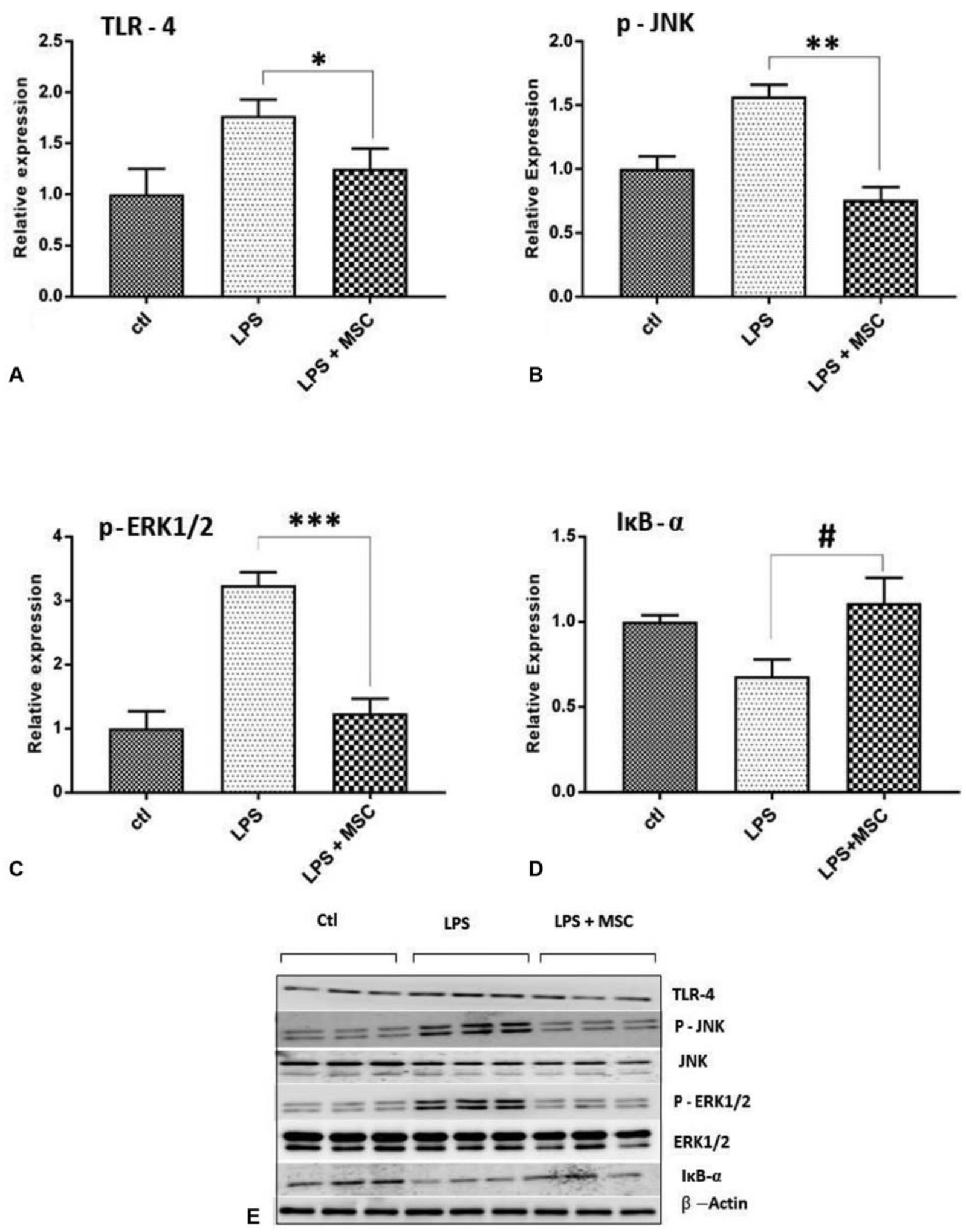

Fig. 2 (A) Western blot analysis of LPS-treated uterine cells showed increased TLR-4 expression, but was attenuated in mesenchymal stem cell cocultures. (B and C) Phosphorylation of c-Jun N-terminal kinase (JNK) and extracellular signaling regulator kinase (ERK1/2) were attenuated in uterine cells treated with LPS and cocultured with mesenchymal stem cells. (D) IKB- $\alpha$ induction was higher in co-cultures of lipopolysaccharidetreated with mesenchymal stem cells. (E) Western blots depiction of the data (E). Data represent mean \pm SE. ${ }^{*} p=0.05,{ }^{* *} p=0.0001$, ${ }^{* * *} p=0.0001,{ }^{\#} p=0.006$. CtI, control; LPS, lipopolysaccharide; SEM, standard error of the mean; TLR, toll-like receptors. 

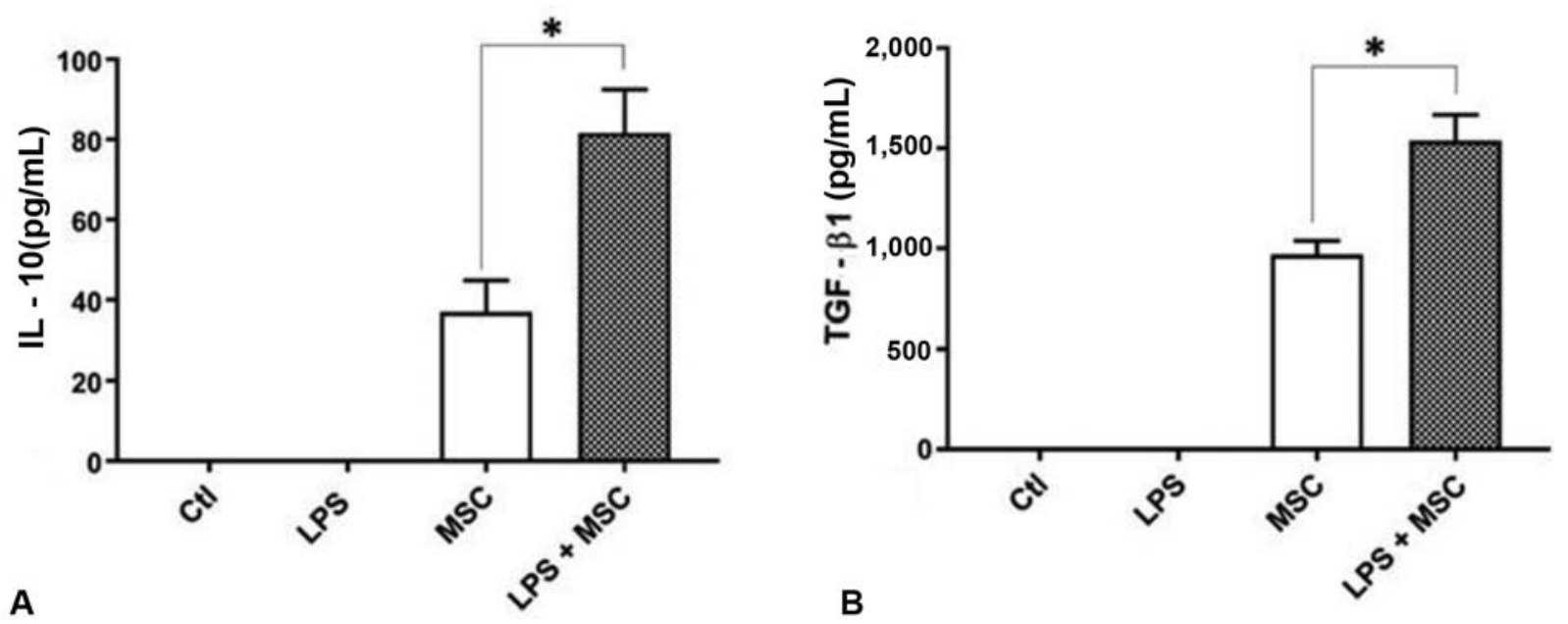

Fig. 3 Lipopolysaccharide (LPS) treated human uterine cells cocultured with mesenchymal stem cells expressed Increased induction of antiinflammatory cytokines IL-10 (A), TGF- $\beta 1$ (B). Data represent mean \pm SE ${ }^{*} p=0.0001$. Ctl, control; IL, interleukin; SE, standard error; TGF, transforming growth factor.

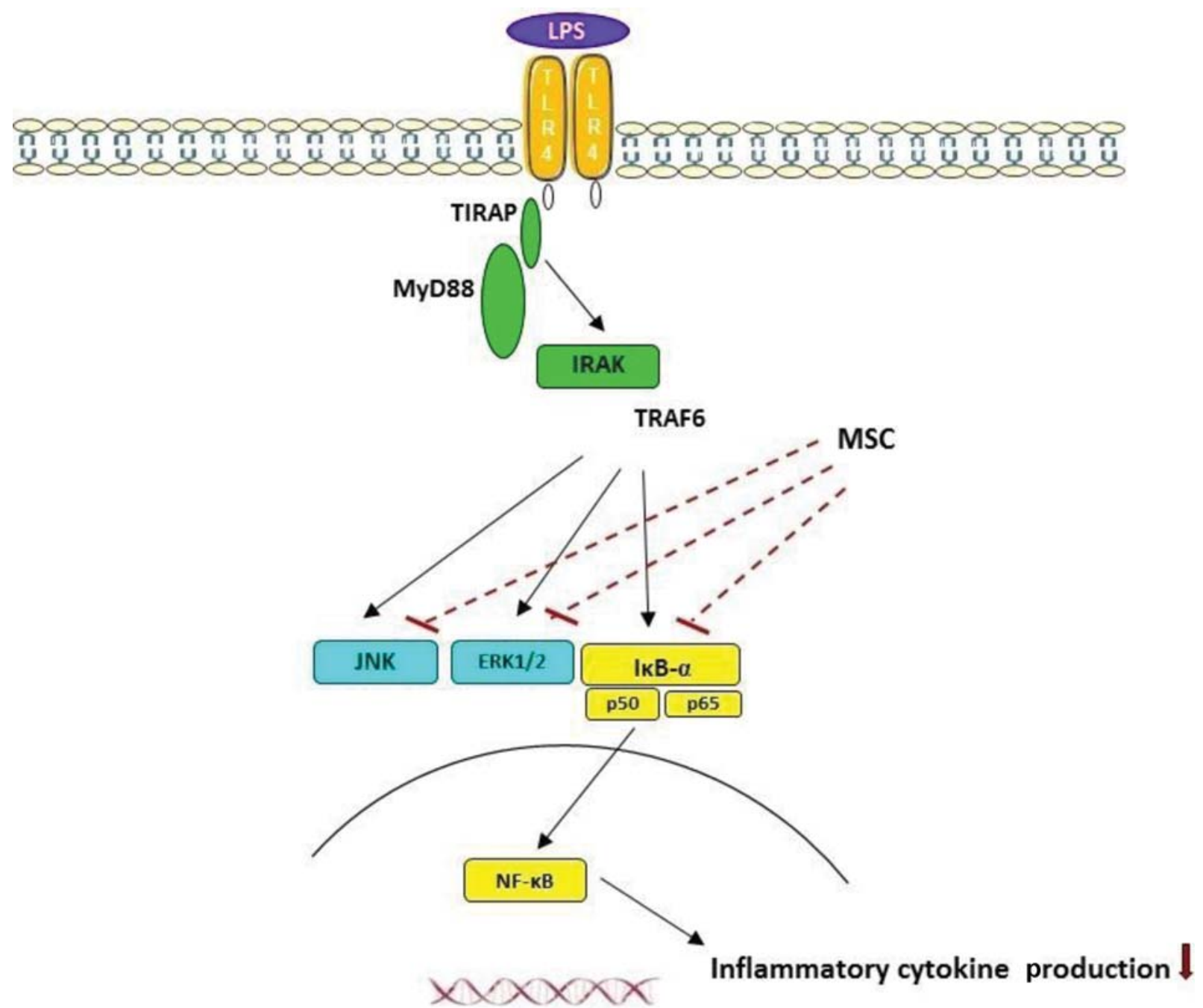

Fig. 4 Schematic diagram depicting mechanism by which MSC's attenuate inflammation in uterine cells exposed to LPS. ERK 122 , extracellular signaling regulator kinase; JNK, c-Jun N-terminal kinase; LPS, lipopolysaccharide; MSC, mesenchymal stem cells; NF, nuclear factor; TIRAP, tollinterleukin 1 receptor adapter protein; MyD88, myeloid differentiation 88; TRAF6, tumor necrosis factor receptor-associated factor 6; IRAK, II-1 receptor-associated kinases. 
ERK1/2. ${ }^{30-33}$ Pathologic inflammation is thought to be one of the primary factors leading to $\mathrm{PTB}^{14}$ and novel, cell-based therapies in women with increased risk of inflammatorymediated preterm birth may fill current therapeutic gaps.

Our MSC cocultures exhibited inhibition of MAPKs pathways, impeding NF-kB expression, thereby dampening the production of inflammatory cytokines IL- 1 and IL- $6^{32}$ (-Fig. 4). Our findings of induced expression of proinflammatory cytokines IL-6 and IL-8 corroborated studies in human endometrial endothelial cells ${ }^{34}$ and other endothelial subtypes. $^{35-37}$ Taken together, the evidence we present suggests that our MSC/myometrial coculture model allows for the efficient in-vitro study of human preterm birth pathophysiology and potential therapeutic interventions along this complex pathway.

The unique characteristic feature of MSCs are self-renewal and multilineage differentiation that together create a potential enduring therapeutic immunomodulatory role. The immunosuppressive properties of MSCs as potential novel modulators of preterm birth leverage their prime role in innate immunity. ${ }^{27}$ Innovative tissue engineering technologies have led to the production of MSC three-dimensional (3D) scaffolds that promote secretion of anti-inflammatory cytokines and reduce inflammatory cell infiltration in nonobstetric applications. ${ }^{38}$ This preclinical work has led to clinical trials of MSCs in various human diseases, such as graft versus host disease, and others. $^{28,29}$ Hallmarks of these collection of investigations include MSCs attenuated expression of proinflammatory cytokines IL-6 and IL- $8^{39-41}$ and increased expression of antiinflammatory cytokines TGF- $\beta 1$ and IL-10. ${ }^{42,43}$ Increased MSC-mediated production of IL-10 by reduces sepsis induced inflammation ${ }^{44}$ and alleviates air way inflammation. ${ }^{45}$ MSC administration has shown specific promise in rodent models of other organ-based injuries, including heart and lung. ${ }^{45,46}$

Our data introduce the provocative hypothesis that MSCmediated production of IL-10 and other soluble factors may have clinical benefit in human preterm birth and other inflammatory reproductive conditions such as uterine fibroid degeneration during pregnancy, chronic placental abruption, intra-abdominal inflammation/appendicitis during pregnancy, and PPROM without infection among others. Only one prior study has assessed the role of stem cells for prevention of preterm birth, and that work was performed in a murine model. ${ }^{23}$ In pregnant mice, pretreatment with MSCs decreased the LPS-induced preterm birth rate by $21 \%$. One promising feature of MSCs was that they also alleviated LPS-induced morphologic changes associated with neurotoxicity and microglial activation suggesting a potential protective role against neurological sequelae. This neuroprotective effect was accompanied by decreased IL- 6 levels in fetal brain and increased IL-10 in dam serum. Additional in vitro and in vivo studies are needed to better elucidate the specific mechanisms involved in MSCs effects in preterm birth.

\section{Conclusion}

In conclusion, the results of this study provide support for an innovative therapeutic paradigm of pregnancy-associated inflammatory pathology. Our data suggest that MSCs mediate immunosuppression of LPS treated uterine cells through TLR-4, MAPK pathways, and modify cytokine expression. While the concept of biology-based therapy in pregnancy presents its own set of investigative and clinical challenges, current therapies have proven inadequate. Since MSCs interpolate themselves into pathologically stimulated uterine tissue, they can provide ongoing immunomodulation which may be superior to single or repetitive dosing of pharmacologic agents tilting the risk/benefit ratio. Further investigations comparing the in-vivo efficacy and side-effect profile of MSCs compared with more traditional anti-inflammatory and neuroprotective agents will help crystallize the feasibility of MSCs as a novel cell-based therapy.

\section{Note}

This study was presented as Posters at the 38th Annual Meeting of the Society for Maternal-Fetal Medicine; January 29 to February 3, 2018; Dallas, TX, and at the 65th Annual Scientific Meeting of the Society for Reproductive Investigation; March 6 to 10, 2018 in San Diego, CA.

\section{Funding}

The study was supported from the Department of Obstetrics, Gynecology, and Reproductive Sciences, UTHealthMcGovern Medical School, Houston TX and The Larry C. Gilstrap, MD, Center for Perinatal and Women's Health Research, University of Texas Health Science Center at Houston.

\section{Conflict of Interest}

None declared.

\section{References}

1 Cappelletti M, Della Bella S, Ferrazzi E, Mavilio D, Divanovic S. Inflammation and preterm birth. J Leukoc Biol 2016;99(01): 67-78

2 Frey HA, Klebanoff MA. The epidemiology, etiology, and costs of preterm birth. Semin Fetal Neonatal Med 2016;21(02):68-73

3 Nadeau HC, Subramaniam A, Andrews WW. Infection and preterm birth. Semin Fetal Neonatal Med 2016;21(02):100-105

4 Martin JA, Hamilton BE, Osterman MJK, Driscoll AK, Drake P. Births: Final Data for 2016. Natl Vital Stat Rep 2018;67(01):1-55

5 Boyle AK, Rinaldi SF, Norman JE, Stock SJ. Preterm birth: Inflammation, fetal injury and treatment strategies. J Reprod Immunol 2017;119:62-66

6 Bollapragada S, Youssef R, Jordan F, Greer I, Norman J, Nelson S. Term labor is associated with a core inflammatory response in human fetal membranes, myometrium, and cervix. Am J Obstet Gynecol 2009;200(01):104.e1-104.e11

7 Peltier MR. Immunology of term and preterm labor. Reprod Biol Endocrinol 2003;1:122

8 Yuan M, Jordan F, McInnes IB, Harnett MM, Norman JE. Leukocytes are primed in peripheral blood for activation during term and preterm labour. Mol Hum Reprod 2009;15(11):713-724

9 Goldenberg RL, Hauth JC, Andrews WW. Intrauterine infection and preterm delivery. N Engl J Med 2000;342(20):1500-1507

10 Agrawal V, Hirsch E. Intrauterine infection and preterm labor. Semin Fetal Neonatal Med 2012;17(01):12-19

11 Kemp MW. Preterm birth, intrauterine infection, and fetal inflammation. Front Immunol 2014;5:574 
12 Mogensen TH. Pathogen recognition and inflammatory signaling in innate immune defenses. Clin Microbiol Rev 2009;22(02): 240-273Table of Contents.

13 Newton K, Dixit VM. Signaling in innate immunity and inflammation. Cold Spring Harb Perspect Biol 2012;4(03):a006049

14 Amirchaghmaghi E, Taghavi SA, Shapouri F, Saeidi S, Rezaei A, Aflatoonian $\mathrm{R}$. The role of toll like receptors in pregnancy. Int $\mathrm{J}$ Fertil Steril 2013;7(03):147-154

15 Elovitz MA, Wang Z, Chien EK, Rychlik DF, Phillippe M. A new model for inflammation-induced preterm birth: the role of platelet-activating factor and Toll-like receptor-4. Am J Pathol 2003;163(05):2103-2111

16 Noguchi T, Sado T, Naruse K, et al. Evidence for activation of Tolllike receptor and receptor for advanced glycation end products in preterm birth. Mediators Inflamm 2010;2010:490406

17 Thaxton JE, Nevers TA, Sharma S. TLR-mediated preterm birth in response to pathogenic agents. Infect Dis Obstet Gynecol 2010; 2010:378472

18 Koga K, Izumi G, Mor G, Fujii T, Osuga Y. Toll-like receptors at the maternal-fetal interface in normal pregnancy and pregnancy complications. Am J Reprod Immunol 2014;72(02):192-205

19 Kawai T, Akira S. The roles of TLRs, RLRs and NLRs in pathogen recognition. Int Immunol 2009;21(04):317-337

20 Guo J, Zheng L, Chen L, et al. Lipopolysaccharide activated TLR4/ NF-KB signaling pathway of fibroblasts from uterine fibroids. Int J Clin Exp Pathol 2015;8(09):10014-10025

21 Lyon D, Cheng CY, Howland L, et al. Integrated review of cytokines in maternal, cord, and newborn blood: part I-associations with preterm birth. Biol Res Nurs 2010;11(04):371-376

22 Sivarajasingam SP, Imami N, Johnson MR. Myometrial cytokines and their role in the onset of labour. J Endocrinol 2016;231(03): R101-R119

23 Lei J, Firdaus W, Rosenzweig JM, et al. Murine model: maternal administration of stem cells for prevention of prematurity. Am J Obstet Gynecol 2015;212(05):639.e1-639.e10

24 Lindström TM, Bennett PR. The role of nuclear factor kappa B in human labour. Reproduction 2005;130(05):569-581

25 Otun HA, MacDougall MW, Bailey J, Europe-Finner GN, Robson SC. Spatial and temporal expression of the myometrial mitogenactivated protein kinases p38 and ERK1/2 in the human uterus during pregnancy and labor. J Soc Gynecol Investig 2005;12(03): 185-190

26 Robertson SA, Wahid HH, Chin PY, Hutchinson MR, Moldenhauer LM, Keelan JA. Toll-like receptor-4: a new target for preterm labour pharmacotherapies? Curr Pharm Des 2018;24(09): 960-973

27 Bhaskar B, Mekala NK, Baadhe RR, Rao PS. Role of signaling pathways in mesenchymal stem cell differentiation. Curr Stem Cell Res Ther 2014;9(06):508-512

$28 \mathrm{Oh} \mathrm{JY}$, Ko JH, Lee HJ, et al. Mesenchymal stem/stromal cells inhibit the NLRP3 inflammasome by decreasing mitochondrial reactive oxygen species. Stem Cells 2014;32(06):1553-1563

29 Sangiorgi B, Panepucci RA. Modulation of immunoregulatory properties of mesenchymal stromal cells by toll-like receptors: potential applications on GVHD. Stem Cells Int 2016; 2016:9434250

30 Zhang ZH, Zhu W, Ren HZ, et al. Mesenchymal stem cells increase expression of heme oxygenase-1 leading to anti-inflammatory activity in treatment of acute liver failure. Stem Cell Res Ther 2017;8(01):70
31 Zhu H, Yang F, Tang B, et al. Mesenchymal stem cells attenuated PLGA-induced inflammatory responses by inhibiting host DC maturation and function. Biomaterials 2015;53:688-698

32 Pedrazza L, Cubillos-Rojas M, de Mesquita FC, et al. Mesenchymal stem cells decrease lung inflammation during sepsis, acting through inhibition of the MAPK pathway. Stem Cell Res Ther 2017;8(01):289

33 Song IH, Jung KJ, Lee TJ, et al. Mesenchymal stem cells attenuate adriamycin-induced nephropathy by diminishing oxidative stress and inflammation via downregulation of the NF-kB. Nephrology (Carlton) 2018;23(05):483-492

34 Krikun G, Trezza J, Shaw J, et al. Lipopolysaccharide appears to activate human endometrial endothelial cells through TLR-4dependent and TLR-4-independent mechanisms. Am J Reprod Immunol 2012;68(03):233-237

35 Faure E, Equils O, Sieling PA, et al. Bacterial lipopolysaccharide activates NF-kappaB through toll-like receptor 4 (TLR-4) in cultured human dermal endothelial cells. Differential expression of TLR-4 and TLR-2 in endothelial cells. J Biol Chem 2000;275(15):11058-11063

36 Arima K, Nasu K, Narahara H, Fujisawa K, Matsui N, Miyakawa I. Effects of lipopolysaccharide and cytokines on production of RANTES by cultured human endometrial stromal cells. Mol Hum Reprod 2000;6(03):246-251

37 Oude Nijhuis CS, Vellenga E, Daenen SM, Kamps WA, De Bont ES. Endothelial cells are main producers of interleukin 8 through Tolllike receptor 2 and 4 signaling during bacterial infection in leukopenic cancer patients. Clin Diagn Lab Immunol 2003;10(04):558-563

$38 \mathrm{Li} \mathrm{H}$, Shen $\mathrm{S}, \mathrm{Fu} \mathrm{H}$, et al. Immunomodulatory functions of mesenchymal stem cells in tissue engineering. Stem Cells Int 2019;2019:9671206

39 Li D, Wang C, Chi C, et al. Bone marrow mesenchymal stem cells inhibit lipopolysaccharide-induced inflammatory reactions in macrophages and endothelial cells. Mediators Inflamm 2016; 2016:2631439

40 Rahmat Z, Jose S, Ramasamy R, Vidyadaran S. Reciprocal interactions of mouse bone marrow-derived mesenchymal stem cells and BV2 microglia after lipopolysaccharide stimulation. Stem Cell Res Ther 2013;4(01):12

41 Cai SX, Liu AR, Chen S, et al. Activation of Wnt/ $\beta$-catenin signalling promotes mesenchymal stem cells to repair injured alveolar epithelium induced by lipopolysaccharide in mice. Stem Cell Res Ther 2015;6:65

42 Kubosch EJ, Heidt E, Bernstein A, Böttiger K, Schmal H. The transwell coculture of human synovial mesenchymal stem cells with chondrocytes leads to self-organization, chondrogenic differentiation, and secretion of TGF $\beta$. Stem Cell Res Ther 2016;7(01):64

43 Zhu H, Xiong Y, Xia Y, et al. Therapeutic effects of human umbilical cord-derived mesenchymal stem cells in acute lung injury mice. Sci Rep 2017;7:39889

44 Németh K, Leelahavanichkul A, Yuen PS, et al. Bone marrow stromal cells attenuate sepsis via prostaglandin $\mathrm{E}(2)$-dependent reprogramming of host macrophages to increase their interleukin-10 production. Nat Med 2009;15(01):42-49

45 Gu W, Song L, Li XM, Wang D, Guo XJ, Xu WG. Mesenchymal stem cells alleviate airway inflammation and emphysema in COPD through down-regulation of cyclooxygenase-2 via p38 and ERK MAPK pathways. Sci Rep 2015;5:8733

46 Martire A, Bedada FB, Uchida S, et al. Mesenchymal stem cells attenuate inflammatory processes in the heart and lung via inhibition of TNF signaling. Basic Res Cardiol 2016;111(05):54 